\title{
AN EXPERIMENTAL SETUP TO EVALUATE INNOVATIVE THERAPY OPTIONS FOR THE ENHANCEMENT OF BONE HEALING USING BMP AS A BENCHMARK - A PILOT STUDY
}

\author{
B. Preininger ${ }^{1,2, *}$, H. Gerigk ${ }^{1}$, J. Bruckner ${ }^{1}$, C. Perka ${ }^{1,2}$, H. Schell ${ }^{1}$, A. Ellinghaus ${ }^{1}$, K. Schmidt-Bleek ${ }^{1}$ and G. Duda ${ }^{1,2}$ \\ ${ }^{1}$ Julius Wolff Institute and Center for Musculoskeletal Surgery, Charité - Universitätsmedizin Berlin, \\ Berlin, Germany \\ ${ }^{2}$ Berlin-Brandenburg Center for Regenerative Therapies, Charité - Universitätsmedizin Berlin, Berlin, Germany
}

\begin{abstract}
Critical or delayed bone healing in rat osteotomy (OT) models is mostly achieved through large defects or instability. We aimed to design a rat OT model for impaired bone healing based on age, gender and parity. The outcome should be controllable through variations of the haematoma in the OT including a bone morphogenetic protein (BMP) 2 guided positive control.

Using external fixation to stabilise femoral a $2 \mathrm{~mm}$ double OT in 12 month old, female Sprague Dawley rats after a minimum of 3 litters healing was characterised following in situ haematoma formation (ISH-group)), transplantation of a BMP charged autologous blood clot (BMP-group) and the artificial blood clot only (ABC-group) into the OT-gap. In vivo micro-computer tomography $(\mu \mathrm{CT})$ scans were performed after 2, 4 and 6 weeks. After 6 weeks specimens underwent histological analyses.

In $\mu \mathrm{CT}$ examinations and histological analyses no bony bridging was observed in all but one animal in the ISHgroup. In the BMP group complete bridging was achieved in all animals. The ABC-group showed less mineralised tissue formation and smaller bridging scores during the course of healing than the ISH-group.

In this pilot study we introduce a model for impaired bone healing taking the major biological risk factors into account. We could show that the in situ fracture haematoma is essential for bone regeneration. Using BMP as a positive control the presented experimental setup can serve to evaluate innovative therapeutical concepts in long bone application.
\end{abstract}

Keywords: bone haematoma, bone morphogenetic protein (BMP), delayed healing model, rat, artificial blood clot.

*Address for correspondence:

Bernd Preininger

Julius Wolff Institut

Augustenburger Platz 1, Forum 4,

D-13353 Berlin, Germany

Telephone Number: +4930450659096

FAX Number: +4930450559969

E-mail: bernd.preininger@charite.de

\section{Introduction}

Enhancement of bone regeneration in impaired healing situations remains a clinical challenge as a significant number of fractures exhibit some kind of disturbed repair (Einhorn, 1995). Such delayed healing situations may be attributed to inadequate reduction or instability of fixation, insufficient local nutritious supply and/or general health of the patient, infection, or simply by the very nature of the insulting trauma. In many cases the source remains unidentified (Giannoudis et al., 2007). Under these circumstances an enhancement of bone healing appears mandatory.

To date, bone morphogenetic proteins (BMP) (BMP2, BMP7 and GDF-5 (BMP-14)) are the only drugs available to enhance bone healing next to traditional techniques which aim to locally supplement bone material through either autologous or allogeneous bone product grafting (Wildemann et al., 2011). Several new drugs and "bioproducts", however, are currently in the stage of development (Chen et al., 2010; Harvey et al., 2010; Tare et al., 2010). In order to be able to evaluate the potential of such newly found therapeutic measures, small animal models are most efficient screening models.

Small animal models, especially in rats, are well established to investigate the course of bone healing (Harrison et al., 2003; Jager et al., 2007; Drosse et al., 2008; Claes et al., 2009; Peters et al., 2009). This is due to the advantages of small animals regarding availability, costs and logistic matters. Moreover, a wide range of reagents such as antibodies, molecular probes and growth factors are available for rats so that the biologic mechanisms underlying the healing process can be elucidated. By the use of osteotomy (OT) models in combination with external fixator devices the mechanical environment can be controlled and kept standardised at high accuracy during the trial (Strube et al., 2008a). Furthermore, the combination of an OT and an external fixator device provides the advantage of minimised interaction between the implant and the healing process at the bone healing site.

Currently available, impaired bone healing models have been designed using large artificial bone and/or soft tissue defects or unstable fixation conditions - factors that under clinical circumstances need either a form of bone and/or soft tissue graft or a change of the fixation regime. In addition, these animal models have mostly been conducted using rather juvenile animals. Factors related to reduced bone mineral density and thereby to higher fracture risk (Demir et al., 2008) as well as to limited bone 
healing capacity, like age (Meyer et al., 2001; Meyer et al., 2006; Strube et al., 2008b) and gender (David et al., 2006; Parker et al., 2007; Yamada et al., 2007 Strube et al., 2009) are inherently considered in osteoporosis models (Kalu, 1991; Duque et al., 2009); yet these factors have not been taken into account so far in bone healing models.

The hypotheses of this work were: i) that in 12-monthold female, ex-breeder Sprague Dawley rats, a $2 \mathrm{~mm}$ femoral OT gap stabilised by an external fixator device would not heal within 6 weeks, whereas by the local application of BMP within a blood clot bony bridging would be achieved (Govender et al., 2002; Einhorn et al., 2003; Wildemann et al., 2011); ii) that the delivery of an autologous blood clot would not alter the healing outcome compared to the group in which native haematoma was allowed to form following the OT.

The aims of this study were: i) to characterise a delayed healing model without large bone and/or soft tissue defects or instability, but with a choice of animals having formally reduced biological bone healing potential; ii) to set a benchmark within the model by the use of the currently solely approved drug therapy for bone healing disorders - BMP. In future, newly developed products for the enhancement of bone healing can be compared to the clinical standard (BMP) within a well-designed animal model at high efficiency.

\section{Materials and Methods}

\section{In vitro fixator testing}

In order to check the suitability of the used fixator devices for the animal model, the range of loading likely to occur during the in vivo experiment was tested in vitro. The testing procedure was performed as described previously (Strube et al., 2008a). In brief: For in vitro mechanical testing, the fixators were mounted on harvested femora of 12-month-old female ex-breeder Sprague-Dawley rats, identical to the ones in in vivo surgery $(n=3)$. An OT was performed after the fixators were mounted on the bones to test the stiffness of the fixator device bridging the OT gap. Specimens were examined using titanium K-wires and cross linked carbon bars mounted at an offset of $7.5 \mathrm{~mm}$ (as described in the surgical technique section). Both ends of the specimens were embedded into custommade casting containers with polymethylmethacrylate (Technovits 3040, Heraeus Kulzer, Wehrheim, Germany). For rotational stability after embedding, a short pin was implanted perpendicular to the bone long axis proximally and distally of the K-wires. The specimens were mounted onto a biomechanical testing machine (ElectroForce ${ }^{\circledR}$ TestBench LM1, Bose, MN, USA). Torsional stiffness was tested at $0.5^{\circ} / \mathrm{s}$ up to $5^{\circ}$ at an axial preload of $0.3 \mathrm{~N}$. Axial stiffness was tested at $1 \mathrm{~mm} / \mathrm{min}$ displacement with a preload of $0.3 \mathrm{~N}$ up to $10 \mathrm{~N}$.

\section{In vivo experimental design}

In a total of 17 female ex-breeder Sprague-Dawley rats (weight: $407 \pm 28 \mathrm{~g}$; minimum 3 litters) a midfemoral double OT was stabilised with an external fixator. One group received no further treatment, leaving the in situ haematoma in the OT gap (ISH, $n=7$ ). In a second group an artificial blood clot was implanted into the OT gap (ABC, $n=5$ ), while in a third group a BMP-charged artificial blood clot was implanted into the OT gap (positive control group (BMP), $n=5)$. In vivo micro-computer tomography $(\mu \mathrm{CT})$ scans and X-rays were performed at 2, 4 and 6 weeks after surgery to monitor bone healing. After 6 weeks the animals were sacrificed. Femora were harvested and underwent histological analysis. All animal experiments were carried out according to the policies and principles established by the AnimalWelfare Act. The design of the animal surgeries was critically reviewed and approved by the local legal representative (Landesamt für Arbeitsschutz, Gesundheitsschutz und technische Sicherheit, Berlin, Germany: G0428/08).

\section{Surgical technique}

Surgery was performed under general anaesthesia. The animals received an intraperitoneal injection with $0.3 \mathrm{mg} /$ kg Medetomidin (Domitor ${ }^{\circledR}$, Pfizer, Karlsruhe, Germany) and $60 \mathrm{mg} / \mathrm{kg}$ Ketamine (Actavis, Langenfeld, Germany). Prior to the operation, all animals were weighed and the left hind portion, including the entire leg, was shaved and disinfected by using povidone-iodine. All animals were subcutaneously injected with an antibiotic $(4 \mathrm{mg} / \mathrm{kg}$ Clindamycin, Ratiopharm, Ulm, Germany). As analgesia the animals received an injection of $20 \mathrm{mg} / \mathrm{kg}$ Tramadol (Tramal ${ }^{\circledR}$, Grünendal Aachen, Germany) directly prior to the surgery. The animals were laid on their right side on a heating plate $\left(37^{\circ} \mathrm{C}\right)$ covered with a sterile sheet leaving the left hind leg uncovered. A longitudinal lateral skin incision was made over the femur. The femur was exposed by blunt dissection of the fascia between the quadriceps and hamstring muscles. A primary stainless steel fixator served as drilling guide to ensure correct and reproducible positioning of the K-wires relative to the bone. Using this drilling guide, the four holes were drilled consecutively with a drill of $0.8 \mathrm{~mm}$ diameter (S-11, Implantmeds, W\&H Oral Surgery, Büromoos, Austria), using constant irrigation ( $0.9 \%$ saline solution) and followed by screwing in the wires bicortically, still using the guide. The template was removed and the cross-linked carbon fixator bar was mounted at an offset of $7.5 \mathrm{~mm}$. The musculature in the middle between the two inner K-wires was then dissected from the bone at a length of approximately $4 \mathrm{~mm}$ and protected by a wound elevator. The femur was double osteotomised ( $0.3 \mathrm{~mm}$ saw blade, S-8R, Implantmeds, W\&H Oral Surgery) in the centre between the two inner $\mathrm{K}$-wires using a $2 \mathrm{~mm}$ saw guide fixed on the $\mathrm{K}$-wires to set a standardised gap size. The bone segment was removed thereafter. Irrigation was performed during cutting to prevent thermal damage to the bone and surrounding tissues and the K-wires were then shortened flush with the bar. The fascia of the muscle was sutured with 3.0 absorbable sutures, the skin then closed with 3.0 nonabsorbable sutures, which were removed after 2 weeks during the wound care routine. The animals were closely monitored during the first three days after surgery. For post-surgery analgesia, the animals received Tramal ${ }^{\circledR}$ in their drinking water $(25 \mathrm{~mL} / \mathrm{L})$ for three days. Afterwards the animals were seen daily, the wound was monitored, and weight was controlled weekly. 
A

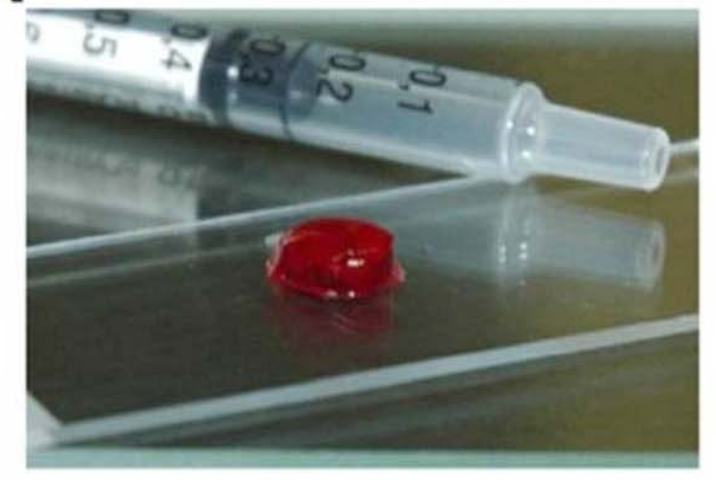

B

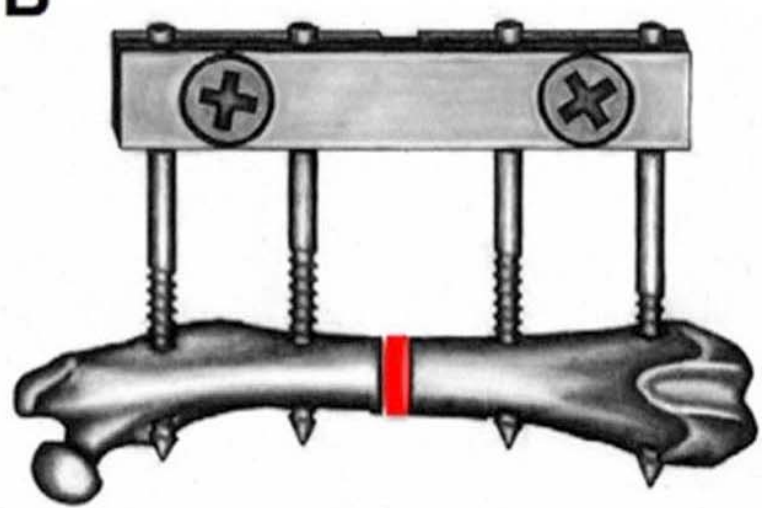

Fig. 1. The artificial blood clot: Depicted next to a $1 \mathrm{~mL}$ syringe for size comparison (A). This blood clot is then inserted in the osteotomy gap of the femur, stabilised with an external fixator $(\mathbf{B})$.

\section{Blood clot formation}

A blood clot composed of $200 \mu \mathrm{L}$ autologous peripheral blood was prepared for each animal at the beginning of the surgical procedure. Peripheral blood was drawn from the saphenous vein from the right shank under general anaesthesia using a $1 \mathrm{~mL}$ syringe prepared with $30 \mu \mathrm{L}$ of citrate (buffered sodium citrate (equivalent to $3.2 \%$ sodium citrate) $0.109 \mathrm{M}$, taken from BD Vacutainer Citrate Plus Plastic Tubes \# 363080, BD Franklin Lakes, NJ, USA) to inhibit the immediate coagulation and keep the blood from clotting. The blood was then filled into the lid of a $1.5 \mathrm{~mL}$ Eppendorf tube (VER International, Darmstadt, Germany) as a form-giving device for the round shape needed to fit into the OT gap (Fig. 1). In the BMP group, rhBMP2 (50 $\mu \mathrm{g}$ of rhBMP-2 (derived from E. coli; (Kubler et al., 1998)) per animal (1 mg/mL, dd $\mathrm{H}_{2} \mathrm{O}$; Prof. Sebald, Würzburg, Germany)) was added before clotting was initiated with the addition of $4 \mu \mathrm{L} \mathrm{CaCl} \cdot 12 \mathrm{H}_{2} \mathrm{O}$ and $4 \mu \mathrm{L}$ thrombin both in the $\mathrm{ABC}$ and in the BMP groups (500 I.E. /mL; Baxter Deutschland, Unterschleißheim, Germany).

\section{In vivo micro computer tomography $(\boldsymbol{\mu C T})$}

Bone healing was assessed by in vivo micro computer tomography $(\mu \mathrm{CT})$ at 2,4 and 6 weeks post-operation. The animals were under general anaesthesia during this procedure (Medetomidin $0.3 \mathrm{mg} / \mathrm{kg}$ (Domitor ${ }^{\circledR}$, Pfizer) and Ketamine $60 \mathrm{mg} / \mathrm{kg}$ (Actavis) i.p.). All femora were scanned using quantitative micro-computed tomography (vivaCT 40, Scanco Medical, Brüttisellen, Switzerland). Scans were reconstructed at $35 \mu \mathrm{m}$ isotropic resolution. A volume of interest (VOI) was defined for the periosteal and endosteal callus, excluding the cortical bone based on inner and outer values for semi-automatic contouring. A 4 $\mathrm{mm}$ volume of interest (VOI) was applied, $2 \mathrm{~mm}$ in each axial direction starting at the centre slice of the osteotomy gap. Accordingly, the VOI included the $2 \mathrm{~mm}$ gap region and $1 \mathrm{~mm}$ in both the proximal and distal directions from the borders of the original OT.

A global threshold for fracture callus at $233 \mathrm{mg} \mathrm{HA} / \mathrm{cm}^{3}$ was manually determined, corresponding to $50 \%$ of the mineralisation of intact cortical bone from the tibia. This value was based on visual inspection of ten random single tomographic slices from each animal's tibia. Outcome

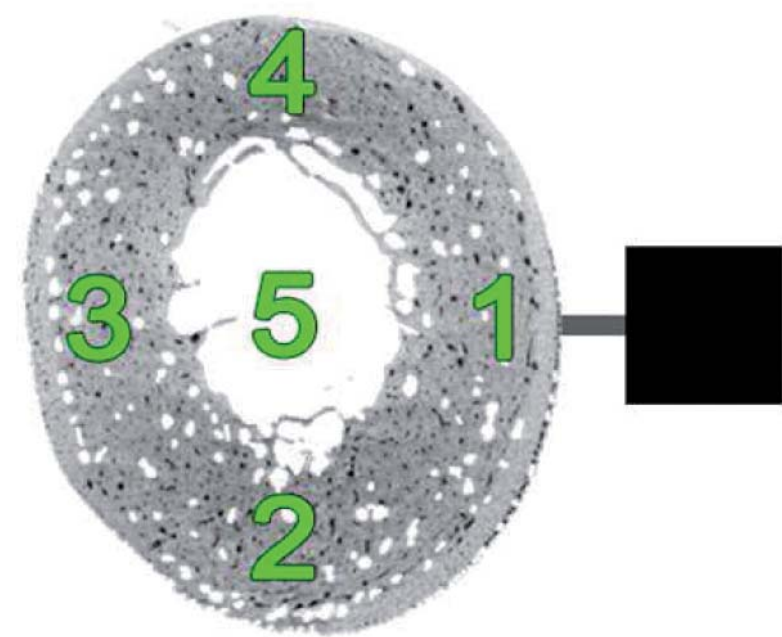

Fig. 2. Five regions within a section through the callus tissue in the VOI (volume of interest) of the $\mu \mathrm{CT}$ evaluation have been defined as indicated by the green numbers. The black square on the right side symbolises the fixator bar and the pins mounted on the lateral side of the femur.

measures included bone volume $\left(\mathrm{BV}, \mathrm{mm}^{3}\right)$, total callus volume $\left(\mathrm{CV}, \mathrm{mm}^{3}\right), \mathrm{BV} / \mathrm{CV}$, and tissue mineral density (TMD, mg HA/ $\mathrm{cm}^{3}$ ). Bone mineral content (BMC) as a product of $\mathrm{BV}$ and TMD was calculated. 3D Pictures were reconstructed using Scanco software.

Furthermore, a score was used to quantify the bridging of the OT gap by mineralised tissue during the course of the experiment. Therefore, in an imaginary perpendicular plane to the length axis of the fixator in the medial region of the gap, mineralised tissue formations bridging the gap were assessed in 5 separate regions (Fig. 2). One blinded scorer evaluated bridging with the help of a 3D-reconstruction of CT-Imaging. In every separate region, bridging was rated 1 for bridging or 0 for non-bridging. The bridging score for every individual animal represents the sum of the scores of every region with a maximum of 5 points.

\section{Histological procedure and analyses}

The femora of the ISH and the ABC group were fixed for 2 days in normal buffered formaldehyde, decalcified 


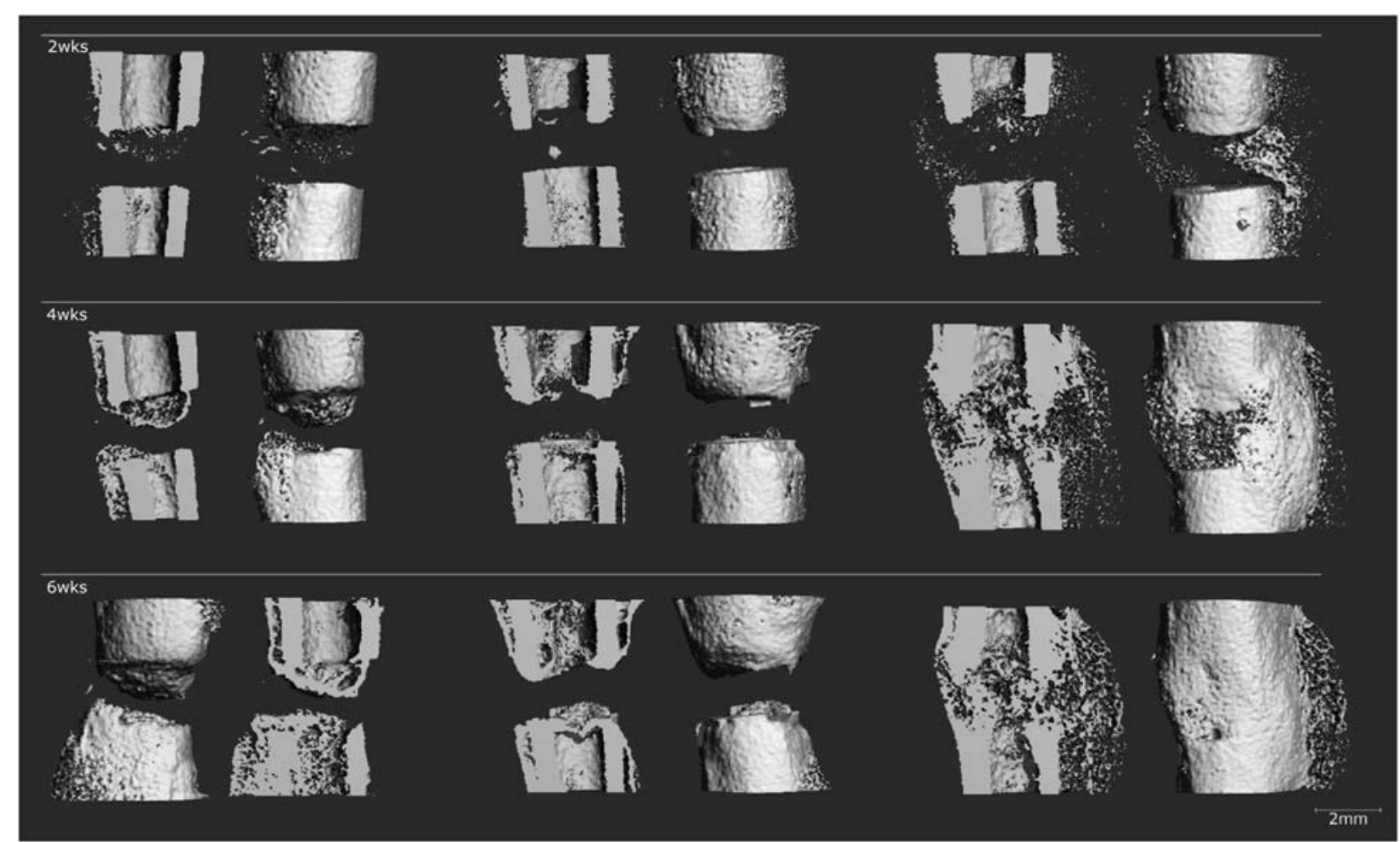

Fig. 3. 3D reconstructions from $\mu \mathrm{CT}$ scans from one representative animal after 2, 4 and 6 weeks of each group are shown. In the ISH group (left) mineralised tissue was formed predominantly at the endosteal regions. After 6 weeks the gap had not been bridged; rather a sealing of the medullary canal was observed. In the ABC group (middle) callus formation was mainly located between the cortices adjoining the gap. Neither bridging nor cap-formation was observed. In the BMP group (right) massive callus formation in the periosteal and intercortical regions was observed between week 2 and 4. Complete bridging with a reformed medullary canal had occurred during the 6 weeks observation period.

in EDTA (42 days at $37^{\circ} \mathrm{C}$ ), dehydrated with alcohol and xylol, and embedded in paraffin. The femora of the BMP group were fixed for 2 days in normal buffered formaldehyde, dehydrated in ethanol, and embedded in polymethylmethacrylate (Technovit1 9100, Heraeus Kulzer). Longitudinal serial sections $(4 \mu \mathrm{m})$ were cut in the plane of the K-wire ducts for all femora.

Sections of each animal were stained with Movat's Pentachrome which allows a distinct and colourful contrast between the different tissue types: haematoma/fibrin is stained different shades of red, cartilage is deep green, fibrous connective tissue is light green-blue and bony tissue is stained yellow (Olah et al., 1977). The sections were analysed for the type of tissue bridging the gap. Thereby we distinguished between mineralised tissue, cartilage tissue and connective tissues within the OT gap region. In case the gap was bridged by mineralised tissue it was further assessed whether the formation occurred in the periosteal or intercortical region.

\section{Statistical analysis}

Mean values together with standard errors were calculated for non-parametric data gained from the $\mu \mathrm{CT}$ analysis. Data comparison was interpreted using the Kruskal-Wallis Test and corrected $p$ values for intergroup comparisons. For statistical analysis SPSS 18.0 for Windows (SPSS Inc.,
Chicago, IL, USA) was used. A $p$ value of less than 0.05 was taken to be a significant difference.

\section{Results}

\section{In vitro testing of the fixator devices}

Torsional and axial loading of the system showed a linear correlation of force and rotation and force and displacement during the test protocol at values of $14.7 \pm 2.1 \mathrm{Nmm} /{ }^{\circ}$ and $57.3 \pm 7.4 \mathrm{~N} / \mathrm{mm}$, respectively.

\section{In vivo $\mu \mathrm{CT}$ - callus formation and bridging of the gap}

During the course of the experiment, mineralised tissue formation at 2, 4 and 6 weeks after OT was observed in in vivo $\mu \mathrm{CT}$. In the ISH there was only very scarce periosteal callus formation without any bridging of the defect zone by mineralised tissue. In the majority of the animals, mineralised callus formation was observed within the gap region. This callus formation, however, did not bridge the gap.

In the $\mathrm{ABC}$ group callus formation only occurred in the intercortical region. The callus formed there, however, did not bridge the gap and was only appositioned at the region directly above the medullary canal. 
Table 1. Parameters retrieved from the $\mu \mathrm{CT}$ given as mean \pm standard deviation (min-max) are grouped by treatment and time points. There was significantly more Callus Volume (CV, BV) in the BMP group than in the other groups ( $p$ $<0.001)$; Within the ISH-group these values were higher than in the ABC-group although not significant $(p<0.2)$. The bone mineral content (BMC) was significantly higher in the BMP group than in the other groups $(p<0.001)$; Within the ISH-group these values again were higher than in the ABC-group although not significant $(p<0.16)$. No significant differences could be observed for BV/CV and TMD between the investigated groups.

\begin{tabular}{|c|c|c|c|}
\hline & BMP & $\mathrm{ABC}$ & $\mathrm{ISH}$ \\
\hline CV & $155 \pm 66(86-243)$ & $20,4 \pm 4,5(14-25)$ & $22,6 \pm 5,8(16,2-29,1)$ \\
\hline BV & $44,5 \pm 16(23-62)$ & $10,1 \pm 2,6(7-13)$ & $12,3 \pm 2,8(10-16)$ \\
\hline $\mathrm{BV} / \mathrm{CV}$ & $0.3 \pm 0.1(0.2-0.5)$ & $0,5 \pm 0,1(0,4-0,6)$ & $0,6 \pm 0,1(0,4-0,6)$ \\
\hline TMD & $573 \pm 14(552-588)$ & $520 \pm 200(160-616)$ & $658,4 \pm 54,7(629-740)$ \\
\hline BMC (BMD) & $25,4 \pm 8,5(14-34)$ & $5,1 \pm 2,2(2,0-7,3)$ & $8,1 \pm 1,7(6-10)$ \\
\hline CV & $161 \pm 52(103-212)$ & $24,8 \pm 8,6(14-34)$ & $36,6 \pm 14,2(17-50)$ \\
\hline BV & $95 \pm 21(78,6-119)$ & $15,0 \pm 6,3(8-22)$ & $24,4 \pm 11,5(9-36)$ \\
\hline $\mathrm{BV} / \mathrm{CV}$ & $0,6 \pm 0,2(0,4-0,8)$ & $0,6 \pm 0,1(0,5-0,7)$ & $0,6 \pm 0,1(0,5-0,7)$ \\
\hline TMD & $658 \pm 35(629-715)$ & $666,3 \pm 35,4(623-708)$ & $672,3 \pm 12,5(663-690)$ \\
\hline BMC (BMD) & $62,5 \pm 14(49,5-78,4)$ & $10,0 \pm 4,1(5,4-14)$ & $16,3 \pm 7,6(6-24)$ \\
\hline CV & $148 \pm 45(95-185)$ & $30,0 \pm 9,6(18-43)$ & $51,2 \pm 24,3(21-80)$ \\
\hline BV & $104 \pm 31(76-152)$ & $22,0 \pm 8,8(12-36)$ & $40,4 \pm 19,8(14-61)$ \\
\hline $\mathrm{BV} / \mathrm{CV}$ & $0,7 \pm 0,1(0,5-0,8)$ & $0,7 \pm 0,1(0,6-0,9)$ & $0,8 \pm 0,1(0,7-0,8)$ \\
\hline TMD & $735 \pm 34(710-792)$ & $725,1 \pm 75,2(603-800)$ & $746,9 \pm 28,1(710-775)$ \\
\hline BMC (BMD) & $75,9 \pm 22(59-113)$ & $15,9 \pm 6,6(8,8-26,5)$ & $30,4 \pm 15,1(10-45)$ \\
\hline
\end{tabular}

Table 2. Bridging scores (mean values) assessed in the $\mu \mathrm{CT}$-normalised versus the number of animals are given. Regions 1-4 (Fig. 2) have been summarised in one column whereas results from the centre region (5) are given in a separate column. Please note that superiority of the BMP group in the bridging score results from higher values only in the peripheral regions 1-4, while in the centre region only a few differences can be observed. (ISH: untreated control group; ABC: artificial clot group; BMP: rhBMP2 treated positive control group; $n$ : number of animals per group; wks: weeks).

\begin{tabular}{ll|lll} 
& & \multicolumn{4}{c}{ bridging score normalized vs. n } \\
\cline { 3 - 5 } group & time point & Zone 1-4 & Zone 5 & $\Sigma$ \\
\hline ISH (n 7) & 2 wks & 0,0 & 0,0 & 0,0 \\
ABC (n 5) & $"$ & 0,0 & 0,0 & 0,0 \\
BMP (n 5) & 4 wks & 0,4 & 0,0 & 0,7 \\
\hline ISH (n 7) & $"$ & 0,0 & 0,0 & 0,0 \\
ABC (n 5) & $"$ & 2,0 & 0,2 & 2,2 \\
BMP (n 5) & 6 wks & 0,6 & 0,3 & 0,9 \\
\hline ISH (n 7) & $"$ & 0,0 & 0,2 & 0,2 \\
ABC (n 5) & $"$ & 3,4 & 0,6 & 4,0 \\
BMP (n 5) & & & &
\end{tabular}

In the BMP group massive callus formation was observed and bridging occurred in all animals already at a 4 week time point. The callus formation was observed predominantly in periosteal and intercortical regions, whereas relatively smaller stimulation of the formation of mineralised tissue within the medullary canal occurred (Fig. 3). During the experiment no pronounced signs of swelling, seroma or prolonged wound secretion were observed in the BMP-Group compared to the two other groups.

\section{Callus volume and quality}

The amount of callus formed increased over time as well as the mineral content of the newly formed tissue in all animals $(p<0.0001)$. At all investigated time points the total volume $(\mathrm{CV})$ of callus formation was significantly higher in the BMP group than in the ISH and the ABC groups $(p<0.0001)$. Moreover, the bone volume (BV) and the tissue mineral content (TMC) in the BMP group were significantly higher at all analysed time points $(p<$ 0.0001 ). Results after 2, 4 and 6 weeks for each group are displayed in Fig. 4 and summarised in Table 1. 

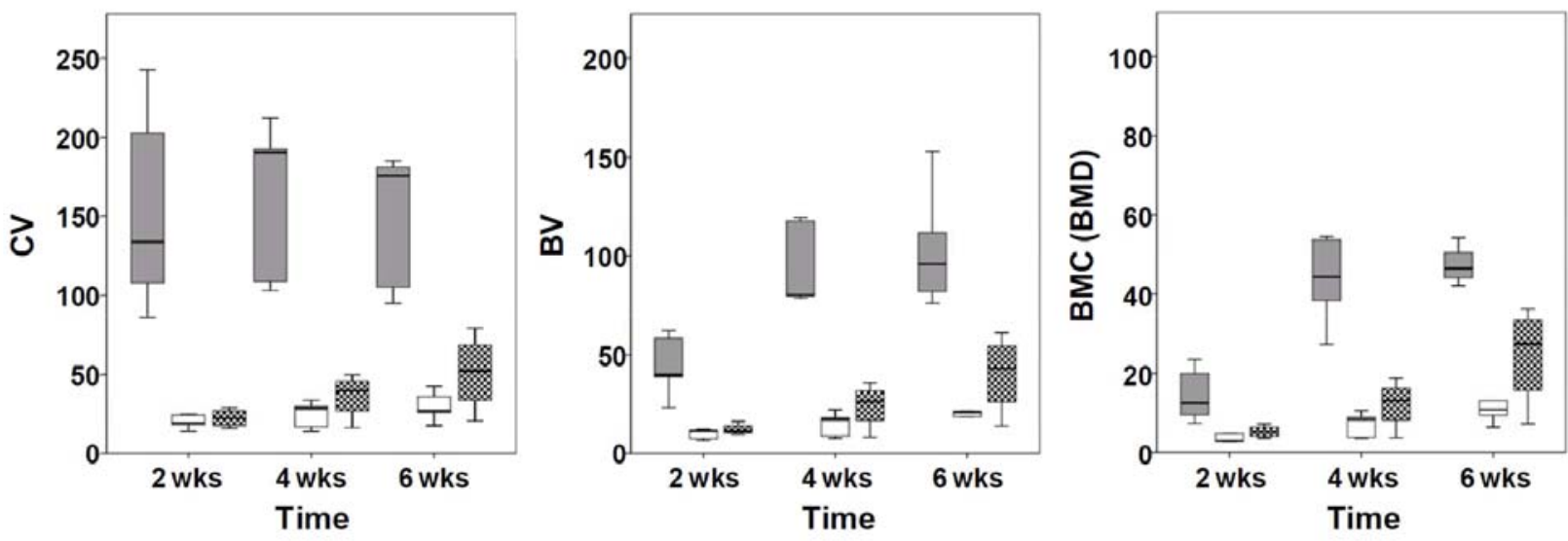

\section{BMP $\square$ ABC $\otimes I S H$}

Fig. 4. An increase of callus volume $\left(\mathrm{CV},\left[\mathrm{mm}^{3}\right]\right)$, the amount of bone of the callus tissue $\left(\mathrm{BV},\left[\mathrm{mm}^{3}\right]\right)$ as well as bone mineral contend (BMC, $[\mathrm{mg}]$ ) on the basis of total mineral density of the callus was observed over time. All of these parameters were significantly higher in the BMP group when compared to those in the ISH and ABC group (KruskalWallis Test $; p<0.0001)$. Note the early callus formation in the BMP group. A tendency towards lesser CV and BMC of callus formation was observed in the ABC group compared to the ISH group (Kruskal-Wallis Test; $p=0.2$ and 0.16, respectively), (CV: total volume, BV: bone volume, BMC: bone mineral content, wks: weeks); (BMP: rhBMP2 treated positive control group = grey; ABC: artificial clot group = white, ISH: untreated control group = chequered).

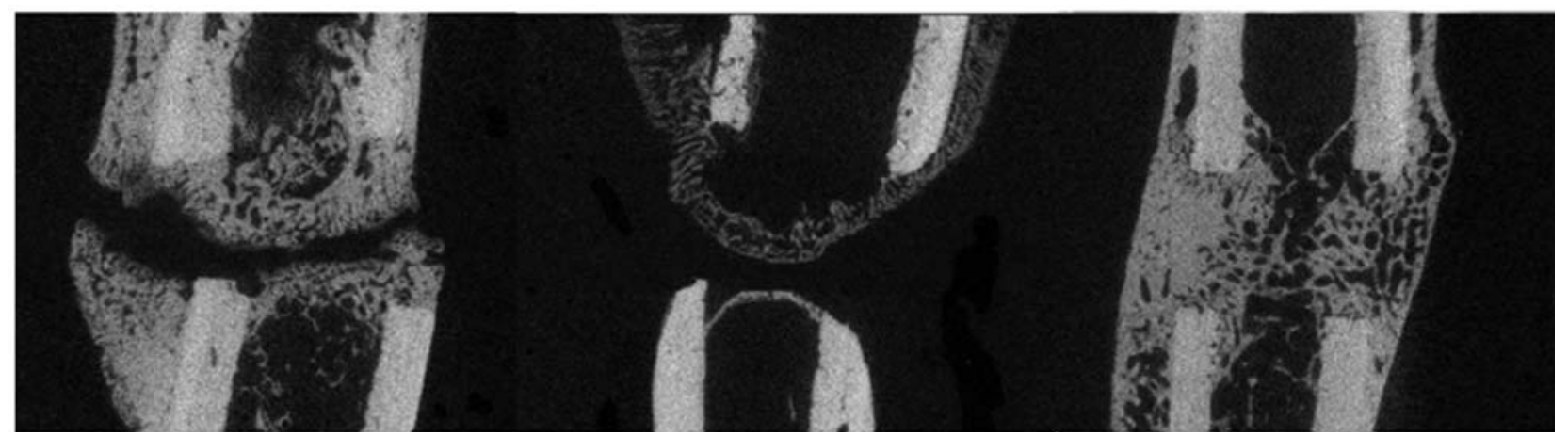

Fig. 5. $\mu \mathrm{CT}$ images of the osteotomy healing progression at 6 weeks post-surgery showing an example of the ISH group on the left, ABC group in the middle, and the BMP group on the right side. Almost no callus formation at the periosteal site can be observed in the ISH and the ABC group while massive periosteal and intercortical callus formations occurred in the BMP group. In the ISH a capping and in the ABC group a sealing of the medullary canal is depicted. Still, it seems that in the ISH group, delayed bridging would be likely to occur while this would not be expected in the ABC group ( $\mu \mathrm{CT}$ : micro computer tomography; ISH: untreated control group; ABC: artificial clot group; BMP: rhBMP2 treated positive control group).

Within the group where the artificial blood clot was transplanted into the OT gap, a tendency towards lesser CV and BMC of callus formation was observed, in comparison to the ISH group ( $p=0.2$ and 0.16 , respectively).

\section{Bridging}

During the course of the experiment no bridging of the OT gap by mineralised tissue was observed in all but one animal of the ISH group. In 5 animals the cap-formation in the centre region bulged into the OT gap, sealing the medullary canal, however, without bridging the gap (Fig. $5)$. In one animal, bridging in 4 out of 5 investigated locations (Fig. 2) occurred at the 6-week time point.

In the $\mathrm{ABC}$ group very little callus formation was observed in the periosteal regions as well as within the gap regions; formations of mineralised tissue without bulging into the medullary canal can be seen here. This was constant for all animals in this group.

In the 3D CT reconstructions from the BMP group, the OT gap was bridged by mineralised tissue at least partly in all animals already after 4 weeks. After 6 weeks, bridging occurred in 4 out of 5 regions in the BMP group. Over the course of the experiment, mineralised tissue formations in the BMP group originated mostly from the periosteal regions (Fig. 5). This was confirmed by the bridging score where differences between the groups were well pronounced in the periosteal regions and only marginally in the centre region. Results of the bridging score are summarised in Table 2. 


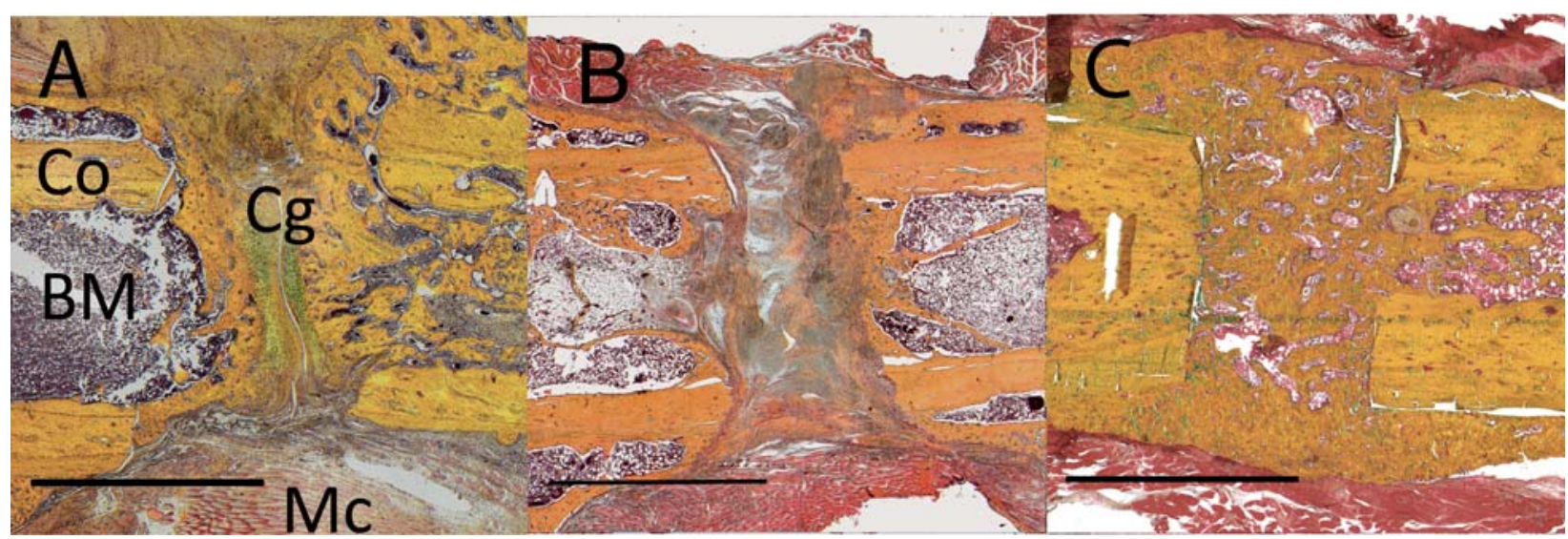

Fig. 6. Photomicrographs of histological sections 6 weeks post-surgery of the (from left to right) ISH, ABC, and BMP group (Movat Pentachrome staining); mineralised formation bulging into the gap region in the ISH group, while in the ABC group almost only fibrous tissue was found, mineralised tissue formation completely bridged and filled the gap within the BMP group (note the predominantly periosteal cantilevered callus formation); (ISH: untreated control group; $\mathrm{ABC}$ : artificial clot group; BMP: rhBMP2 treated positive control group); scale bar: $2.5 \mathrm{~mm}$; Co = cortical bone/ yellow; $\mathrm{BM}=$ bone marrow/ dark red; $\mathrm{Cg}=$ cartilage/ green; $\mathrm{Mc}=$ muscle/ red.

\section{Histology}

The results found in the $\mu \mathrm{CT}$ were supported by the histological observations - all but one animal in the ISH group showed no bony bridging. In these specimens some woven bone formation could be observed in the periosteal and endosteal regions. After 6 weeks the defect zone, however, was predominantly filled with non-mineralised cartilage formation growing from the proximal and distal end of the OT gap and fibrous tissue formation intersecting those cartilage areas (Fig. 6A).

In the $\mathrm{ABC}$ group the gap regions were mainly filled with fibrous tissue; only very little formation of mineralised tissue and cartilage were observed here. As found in the $\mu \mathrm{CT}$ analysis mineralised tissue apposition was only seen above the opening of the medullary canal (Fig. 6B).

Again confirming the results from the $\mu \mathrm{CT}$ in all sections in the BMP group we observed complete bridging of the fracture gap by mineralised tissue in the periosteal and intercortical regions. Callus formations were much more pronounced in the periosteal regions where impressive woven bone formations bridged the gap. Hardly any cartilage formation could be seen in those sections at the 6 week time point (Fig. 6C).

\section{Discussion}

In this study we characterised a delayed bone healing model without the use of large defects, instable fixation or structural damage to the adjacent soft tissues but rather with a choice of animals having formally reduced biological bone healing potential. In our experiment we integrated the clinical standard to treat impaired bone healing as a positive control. Due to our experimental design we do have a clinical relevant benchmark to quantify the effectiveness of innovative therapies. In our model, the BMP stimulated group showed complete bone healing within 6 weeks while the untreated group resulted in an impaired healing situation. These observations go along with the experiments of Wildemann et al. (Wildemann et al., 2011), where an intramedullary nail coated with BMP was capable of rescuing a non union in a rat model. The early formations of mineralised callus tissue support the results from Wulsten et al. (Wulsten et al., 2011) where BMP induced a very early callus formation and thereby stiffening these callus formations. Interestingly, we found that the pure, artificial haematoma from peripheral blood used as a carrier for BMP negatively influenced the outcome of the repair process.

In this model, the healing outcome of our newly developed model can be controlled from non-healing to complete bridging within 6 weeks by simply altering the haematoma filling the OT gap without the use of a structure-providing scaffold.

The setup characterised within our experiments now enables us to compare newly developed products for the enhancement of bone healing to the current clinical standard under circumstances resembling an efficient, reproducible model for delayed bone healing. Innovative therapy approaches (Chen et al., 2010; Harvey et al., 2010; Tare et al., 2010) delivered via the haematoma, as well as various physiological and pathological alterations of the osteotomy haematoma can be characterised, and its effect on the formation of new bone can be investigated.

A limitation of this study is the use of two embedding methods for samples from the ISH \& ABC group and the BMP group, due to further analyses of mechanical properties of the callus tissue in the latter group. In order to exclude possible methodological errors arising from automatic picture processing with quantitative or semiquantitative histomorphometric methods we analysed our samples by hand and carried out descriptive histology only.

The OT gap is filled with a haematoma when left alone. This in situ haematoma in itself has a certain healing potential (Schmidt-Bleek et al., 2009; Kolar et al., 2010). We predominantly found fibrous tissue with small cartilage 
appositions within the gap zone. Formations of immature woven bone were detected at endosteal and periosteal sites but rarely in the OT gap. The gap regions were mainly filled with areas of cartilage mostly separated by a central layer of fibrous tissues. According to a histological scale of fracture healing (Oetgen et al., 2008) this tissue formations found in the ISH group at 6 weeks correspond to very immature stages of bone healing.

The haematoma, however, could serve as a carrier for growth factors or cells (Trombi et al., 2008) as therapeutics to enhance bone healing. In this study the in situ haematoma was replaced with an artificial haematoma, derived from autologous peripheral blood. This artificial haematoma showed a tendency to lessen callus formation compared to the in situ haematoma with an increased fibrous tissue share in the gap region construing towards a pseudarthrotic outcome. This could be due to the interrupted coagulation process necessary to prepare the artificial haematoma. By this, the cytokine pattern in the haematoma could be altered. The thrombin used in the process of clotting the artificial blood clot has been reported to trigger the release of growth factors known to positively influence osteogenic and angiogenic processes (Martineau et al., 2004). Therefore, it could be presumed that the clot itself should further the healing process and in converse argument the negative outcome of the healing in the $\mathrm{ABC}$ group is unexpected. More and more evidence, however, arises, that the balanced and proper temporal and spatial sequence of factors during the initial phase of bone healing is important for a successful healing outcome (Mountziaris et al., 2011). The diminished healing potential of the artificial haematoma, compared with the in situ haematoma observed in this study, is another indicator of the clear impact that the sensitively balanced composition of the haematoma has on the healing process. In the bone haematoma, the first steps of the healing cascade evolve directly after the injury occurs; differing between good and bad healers and bone and soft tissue injury. These differences include a change in the cytokine pattern and cellular composition (Schmidt-Bleek et al., 2009; Recknagel et al., 2011; Recknagel et al., 2012; SchmidtBleek et al., 2012). Therefore, a difference in the healing potential of the in situ haematoma and the artificial blood clot could well be explained by the undisturbed cytokine pattern development in the in situ haematoma.

Nevertheless, though the artificial blood clot is in principle inferior to the in situ haematoma, it still represents a suitable and easy-to-fabricate carrier for products to enhance the healing process. Through manipulation of the artificial haematoma (here the addition of BMP), successful bone healing was achieved in the course of 6 weeks among the biologically-impaired animals investigated. Typical periosteal callus formation could be observed. These formations are in good accordance with the reports found in the literature where the effect of BMP on the periosteal callus formation within the first 4 weeks post osteotomy has been described (Schmidmaier et al., 2002; Wildemann et al., 2011; Wulsten et al., 2011).

In this setup, the naturally occurring fracture haematoma can be mimicked and modified and just-on-time therapy strategies can be tested since there is no incubation time, no toxicity aspects, no adverse immune reaction, and no degradation problem to be antagonised.

Despite the acceptance of the influence of the mechanical environment on the course of bone healing, the mechanical boundary conditions of the animal models used have been characterised only in very few studies. We found our device to be stiffer in torsion and axial compression than those characterised by Strube et al. (Strube et al., 2009), but very good in comparison to those in the study of Mehta et al., 2010 (Mehta et al., 2010). Disadvantages of external fixator devices are soft tissue irritation, pin breakage and pin infection. Nonetheless we observed no breaking of pins or soft tissue irritation in our study. Moreover, by abstaining from the use of instable fixation techniques, the biological processes are not further influenced and hindered by unphysiological interfragmentary movement amplitudes.

Due to our fixator material selection, artefacts caused by the device during $\mu \mathrm{CT}$ could obviously be reduced (Sullivan et al., 1994; Strube et al., 2008a). Thereby, a $3 \mathrm{D}$ radiological in vivo follow-up of callus formation within one animal is possible, while taking advantage of the small interference of the implant material with the healing zone. Geometrical pathways of callus formation can also be followed up and the therapeutic effect of distinct variations of the haematoma can be evaluated for each animal individually. Within our settings now, therapeutics can be tested quantitatively versus the current clinically standardised usage of BMP in treating fracture non-unions.

\section{Conclusion}

The small animal model presented in this pilot study employs risk factors that are likely to coincide with impaired healing situations in the clinic leading to a compromised healing situation. In this experiment, we did not create a large defect and that allows us to abandon the use of a stability providing scaffold. This enabled us to demonstrate the key role of the in situ fracture haematoma during bone regeneration. A simple autologous blood clot enriched with BMP stimulates the model to complete healing within 6 weeks and thereby sets a benchmark for innovative therapies to improve impaired long bone healing situations.

\section{Acknowledgements}

The authors thank Liliya Schumann, Martin Textor and Mario Thiele for providing excellent technical assistance. The manuscript has been professionally edited by Dr. Kastner from "Acaman Academic Manuscripts". The authors report that no competing financial interests exist.

\section{References}

Chen FM, Zhang J, Zhang M, An Y, Chen F, Wu ZF (2010) A review on endogenous regenerative technology in periodontal regenerative medicine. Biomaterials 31: 7892-7927. 
Claes L, Blakytny R, Gockelmann M, Schoen M, Ignatius A, Willie B (2009) Early dynamization by reduced fixation stiffness does not improve fracture healing in a rat femoral osteotomy model. J Orthop Res 27: 22-27.

David V, Lafage-Proust MH, Laroche N, Christian A, Ruegsegger P, Vico L (2006) Two-week longitudinal survey of bone architecture alteration in the hindlimbunloaded rat model of bone loss: sex differences. Am J Physiol Endocrinol Metab 290: E440-447.

Demir B, Haberal A, Geyik P, Baskan B, Ozturkoglu E, Karacay O, Deveci S (2008) Identification of the risk factors for osteoporosis among postmenopausal women. Maturitas 60: 253-256.

Drosse I, Volkmer E, Seitz S, Seitz H, Penzkofer R, Zahn K, Matis U, Mutschler W, Augat P, Schieker M (2008) Validation of a femoral critical size defect model for orthotopic evaluation of bone healing: a biomechanical, veterinary and trauma surgical perspective. Tissue Eng Part C Methods 14: 79-88.

Duque G, Rivas D, Li W, Li A, Henderson JE, Ferland G, Gaudreau P (2009) Age-related bone loss in the LOU/c rat model of healthy ageing. Exp Gerontol 44: 183-189.

Einhorn TA (1995) Enhancement of fracture-healing. J Bone Joint Surg Am 77: 940-956.

Einhorn TA, Majeska RJ, Mohaideen A, Kagel EM, Bouxsein ML, Turek TJ, Wozney JM (2003) A single percutaneous injection of recombinant human bone morphogenetic protein-2 accelerates fracture repair. J Bone Joint Surg Am 85-A: 1425-1435.

Giannoudis PV, Einhorn TA, Marsh D (2007) Fracture healing: the diamond concept. Injury 38 Suppl 4: S3-6.

Govender S, Csimma C, Genant HK, Valentin-Opran A, Amit Y, Arbel R, Aro H, Atar D, Bishay M, Borner MG, Chiron P, Choong P, Cinats J, Courtenay B, Feibel R, Geulette B, Gravel C, Haas N, Raschke M, Hammacher E, van der Velde D, Hardy P, Holt M, Josten C, Ketterl RL, Lindeque B, Lob G, Mathevon H, McCoy G, Marsh D, Miller R, Munting E, Oevre S, Nordsletten L, Patel A, Pohl A, Rennie W, Reynders P, Rommens PM, Rondia J, Rossouw WC, Daneel PJ, Ruff S, Ruter A, Santavirta S, Schildhauer TA, Gekle C, Schnettler R, Segal D, Seiler H, Snowdowne RB, Stapert J, Taglang G, Verdonk R, Vogels L, Weckbach A, Wentzensen A, Wisniewski T (2002) Recombinant human bone morphogenetic protein-2 for treatment of open tibial fractures: a prospective, controlled, randomized study of four hundred and fifty patients. J Bone Joint Surg Am 84-A: 2123-2134.

Harrison LJ, Cunningham JL, Stromberg L, Goodship AE (2003) Controlled induction of a pseudarthrosis: a study using a rodent model. J Orthop Trauma 17: 11-21.

Harvey EJ, Henderson JE, Vengallatore ST (2010) Nanotechnology and bone healing. J Orthop Trauma 24 Suppl 1: S25-30.

Jager M, Degistirici O, Knipper A, Fischer J, Sager M, Krauspe R (2007) Bone healing and migration of cord blood-derived stem cells into a critical size femoral defect after xenotransplantation. J Bone Miner Res 22: 12241233.

Kalu DN (1991) The ovariectomized rat model of postmenopausal bone loss. Bone Miner 15: 175-191.
Kolar P, Schmidt-Bleek K, Schell H, Gaber T, Toben D, Schmidmaier G, Perka C, Buttgereit F, Duda GN (2010) The early fracture hematoma and its potential role in fracture healing. Tissue Eng Part B Rev 16: 427-434.

Kubler NR, Reuther JF, Faller G, Kirchner T, Ruppert R, Sebald W (1998) Inductive properties of recombinant human BMP-2 produced in a bacterial expression system. Int J Oral Maxillofac Surg 27: 305-309.

Martineau I, Lacoste E, Gagnon G (2004) Effects of calcium and thrombin on growth factor release from platelet concentrates: kinetics and regulation of endothelial cell proliferation. Biomaterials 25: 4489-4502.

Mehta M, Strube P, Peters A, Perka C, Hutmacher D, Fratzl P, Duda GN (2010) Influences of age and mechanical stability on volume, microstructure, and mineralization of the fracture callus during bone healing: is osteoclast activity the key to age-related impaired healing? Bone 47: 219-228.

Meyer RA, Jr, Tsahakis PJ, Martin DF, Banks DM, Harrow ME, Kiebzak GM (2001) Age and ovariectomy impair both the normalization of mechanical properties and the accretion of mineral by the fracture callus in rats. J Orthop Res 19: 428-435.

Meyer RA, Jr, Desai BR, Heiner DE, Fiechtl J, Porter S, Meyer MH (2006) Young, adult, and old rats have similar changes in mRNA expression of many skeletal genes after fracture despite delayed healing with age. J Orthop Res 24: 1933-1944.

Mountziaris PM, Spicer PP, Kasper FK, Mikos AG (2011) Harnessing and modulating inflammation in strategies for bone regeneration. Tissue Eng Part B Rev 17: 393-402.

Oetgen ME, Merrell GA, Troiano NW, Horowitz MC, Kacena MA (2008) Development of a femoral non-union model in the mouse. Injury 39: 1119-1126.

Olah AJ, Simon A, Gaudy M, Herrmann W, Schenk RK (1977) Differential staining of calcified tissues in plastic embedded microtome sections by a modification of Movat's pentachrome stain. Stain Technol 52: 331-337.

Parker MJ, Raghavan R, Gurusamy K (2007) Incidence of fracture-healing complications after femoral neck fractures. Clin Orthop Relat Res 458: 175-179.

Peters A, Toben D, Lienau J, Schell H, Bail HJ, Matziolis G, Duda GN, Kaspar K (2009) Locally applied osteogenic predifferentiated progenitor cells are more effective than undifferentiated mesenchymal stem cells in the treatment of delayed bone healing. Tissue Eng Part A 15: 2947-2954.

Recknagel S, Bindl R, Kurz J, Wehner T, Ehrnthaller C, Knoferl MW, Gebhard F, Huber-Lang M, Claes L, Ignatius A (2011) Experimental blunt chest trauma impairs fracture healing in rats. J Orthop Res 29: 734-739.

Recknagel S, Bindl R, Kurz J, Wehner T, Schoengraf P, Ehrnthaller C, Qu H, Gebhard F, Huber-Lang M, Lambris JD, Claes L, Ignatius A (2012) C5aR-antagonist significantly reduces the deleterious effect of a blunt chest trauma on fracture healing. J Orthop Res 30: 581-586.

Schmidmaier G, Wildemann B, Cromme F, Kandziora F, Haas NP, Raschke M (2002) Bone morphogenetic protein-2 coating of titanium implants increases biomechanical 
strength and accelerates bone remodeling in fracture treatment: a biomechanical and histological study in rats. Bone 30: 816-822.

Schmidt-Bleek K, Schell H, Kolar P, Pfaff M, Perka C, Buttgereit F, Duda G, Lienau J (2009) Cellular composition of the initial fracture hematoma compared to a muscle hematoma: a study in sheep. J Orthop Res 27: 1147-1151.

Schmidt-Bleek K, Schell H, Schulz N, Hoff P, Perka C, Buttgereit F, Volk HD, Lienau J, Duda GN (2012) Inflammatory phase of bone healing initiates the regenerative healing cascade. Cell Tissue Res 347: 567573.

Strube P, Mehta M, Putzier M, Matziolis G, Perka C, Duda GN (2008a) A new device to control mechanical environment in bone defect healing in rats. J Biomech 41: 2696-2702.

Strube P, Sentuerk U, Riha T, Kaspar K, Mueller M, Kasper G, Matziolis G, Duda GN, Perka C (2008b) Influence of age and mechanical stability on bone defect healing: age reverses mechanical effects. Bone 42: 758764.

Strube P, Mehta M, Baerenwaldt A, Trippens J, Wilson CJ, Ode A, Perka C, Duda GN, Kasper G (2009) Sexspecific compromised bone healing in female rats might be associated with a decrease in mesenchymal stem cell quantity. Bone 45: 1065-1072.

Sullivan PK, Smith JF, Rozzelle AA (1994) Cranioorbital reconstruction: safety and image quality of metallic implants on CT and MRI scanning. Plast Reconstr Surg 94: 589-596.

Tare RS, Kanczler J, Aarvold A, Jones AM, Dunlop DG, Oreffo RO (2010) Skeletal stem cells and bone regeneration: translational strategies from bench to clinic. Proc Inst Mech Eng H 224: 1455-1470.

Trombi L, Mattii L, Pacini S, D’Alessandro D, Battolla B, Orciuolo E, Buda G, Fazzi R, Galimberti S, Petrini M (2008) Human autologous plasma-derived clot as a biological scaffold for mesenchymal stem cells in treatment of orthopedic healing. J Orthop Res 26: 176-183.

Wildemann B, Lange K, Strobel C, Fassbender M, Willie B, Schmidmaier G (2011) Local BMP-2 application can rescue the delayed osteotomy healing in a rat model. Injury 42: 746-752.

Wulsten D, Glatt V, Ellinghaus A, Schmidt-Bleek K, Petersen A, Schell H, Lienau J, Sebald W, Ploger F, Seemann P, Duda GN (2011) Time kinetics of bone defect healing in response to BMP-2 and GDF-5 characterised by in vivo biomechanics. Eur Cell Mater 21: 177-192.

Yamada M, Briot J, Pedrono A, Sans N, Mansat P, Mansat M, Swider P (2007) Age- and gender-related distribution of bone tissue of osteoporotic humeral head using computed tomography. J Shoulder Elbow Surg 16: 596-602.

\section{Discussion with Reviewers}

Reviewer I: This manuscript introduces an animal model to investigate the influence of an interfragmentary artificially modified haematoma to induce fracture healing. A similar animal model has already been used recently to assess the fracture healing in systemic inflammation by Recknagel et al. (2011) (text reference). However, the experimental setup in the present study offers the advantage to further assess the impact of therapeutic concepts to induce fracture healing under in vivo circumstances. Please comment.

Authors: It has been shown in a similar experimental setup by Recknagel et al. (2011) that an inflammatory response mediated by cytokines such as Il- $1 \beta$, TNF- $\alpha$, IL- 6 etc. can cause impaired bone healing. Although in the present study surgery was carried out in sterile circumstances and animals have been treated with antibiotics during surgery, it would have been favourable to rule out any inflammation. Thus, analysis of the data could benefit from the determination of inflammatory cytokines in the serum before surgery and during the experimental setup and additional immunohistochemical staining at the end of the experimental setup. In my opinion, the effect of an inflammatory response, which additionally influences bone healing mediated by the interfragmentary haematoma should be further taken into consideration.

The animals did not show clinical sings of local infections, such as swelling, rubor or prolonged secretion of the wound, which are often observed in clinical routine after the local application of BMPs. We therefore did not believe an inflammatory reaction caused by possibly microbiological infection would cause the healing alterations. We "ruled out" an inflammation clinically.

Immunohistochemical staining was conducted to stain the endothelial cells expression vWF to make vessel formations clear.

The time point for the histological sections in our experiment was chosen in order to analyse callus formations. Cytokine expressions vary considerably within the very beginning of the healing phase (Recknagel et al., 2011). Therefore immunohistochemical stainings were not conducted at that time point.

We further believe that any alteration between a cytokine expression in the very early phase of fracture healing in this presented experiment is caused by the different cytokine contents and concentrations of the transplanted graft consisting either of pure fracture haematoma, peripheral blood or peripheral blood + BMP2, respectively. However, as this study mainly focused on the establishment of the model with the possible use of the artificial haematoma as carrier for growth factors / cells the different inflammatory reaction during the inflammatory bone healing phase were not addressed. This could be an interesting research option in another study.

Taken together, the findings presented in the manuscript appear to be of a great interest within its field. Therefore, the animal model presented offers a promising alternative to further investigate and promote bone healing under impaired circumstances.

Reviewer II: The lack of mechanical testing, in light of the extensive literature in the field using the particular, well-known, candidate selected, is a major concern. Also in light of the effects of BMP-2 upon cell differentiation, it would be necessary to include data on gene expression profiles. Please comment. 
Authors: The biomechanical testing was performed for the investigated groups, However, results were only obtained for the BMP group (as shown above) while the other groups did not show enough stability in this biologically impaired healing model of old, female, high parity rats with a 2 mm gap size. With the $\mu \mathrm{CT}$ evaluation and the histology, nevertheless, a good impression of the healing outcome was obtained to support the usefulness of the haematoma as a scaffold for growth factor or cell application. As the cascade of the BMP signalling pathway in bone healing has been investigated before (Schwappacher et al., 2009; Sieber et al., 2009; Wagner et al., 2010; Heining et al., 2011; Pohl et al., 2012; Ruschke et al., 2012) (additional references), to only mention some from our Berlin cooperation, we did not see the necessity to include this in our analysis of the model establishment.

Reviewer III: If you use immunohistochemistry technology, would not you be able to figure out difference between ectopic blood clot and in situ blood clot?

Authors: The time point for the histological sections in our experiment was chosen in order to analyse callus formations. Cytokine expressions vary considerably within the very beginning of the healing phase (Recknagel et al., 2011). Therefore, immunohistochemical stainings were not conducted at the here chosen time point. We further believe that any alteration between a cytokine expression in the very early phase of fracture healing, in this presented experiment, is caused by the different cytokine contents and concentrations of the transplanted graft consisting either of pure fracture haematoma, peripheral blood or peripheral blood + BMP2, respectively.

\section{Additional References}

Heining E, Bhushan R, Paarmann P, Henis YI, Knaus P (2011) Spatial segregation of BMP/Smad signaling affects osteoblast differentiation in $\mathrm{C} 2 \mathrm{C} 12$ cells. PLoS One 6: e25163.

Pohl TL, Boergermann JH, Schwaerzer GK, Knaus P, Cavalcanti-Adam EA (2012) Surface immobilization of bone morphogenetic protein 2 via a self-assembled monolayer formation induces cell differentiation. Acta Biomater 8: 772-780.

Ruschke K, Hiepen C, Becker J, Knaus P (2012) BMPs are mediators in tissue crosstalk of the regenerating musculoskeletal system. Cell Tissue Res 347: 521-544.

Schwappacher R, Weiske J, Heining E, Ezerski V, Marom B, Henis YI, Huber O, Knaus P (2009) Novel crosstalk to BMP signalling: cGMP-dependent kinase I modulates BMP receptor and Smad activity. EMBO J 28: 1537-1550.

Sieber C, Kopf J, Hiepen C, Knaus P (2009) Recent advances in BMP receptor signaling. Cytokine Growth Factor Rev 20: 343-355.

Wagner DO, Sieber C, Bhushan R, Borgermann JH, Graf D, Knaus P (2010) BMPs: from bone to body morphogenetic proteins. Sci Signal 3: $\mathrm{mr}$. 